\title{
The first report of two cases of cystic echinococcosis in the lung by Echinococcus ortleppi infection, in Vietnam
}

This article was published in the following Dove Press journal:

Research and Reports in Tropical Medicine

27 March 2017

Number of times this article has been viewed

\author{
Nguyen Van $\mathrm{De}^{\prime}$ \\ Duyet Le Van ${ }^{2}$ \\ 'Department of Parasitology, Hanoi \\ Medical University of Vietnam, \\ ${ }^{2}$ Clinical Laboratories, National \\ Hospital of Tropical Diseases, Hanoi, \\ Vietnam
}

\begin{abstract}
In 2013, two cases of infection by Echinococcus that caused cystic echinococcosis in the lungs were reported. In the first case, there was a cyst of $6 \times 7 \mathrm{~cm}$ in diameter, and in the second case, there were four cysts of $5 \times 6 \mathrm{~cm}, 4 \times 4 \mathrm{~cm}, 3.5 \times 3 \mathrm{~cm}$ and $2.5 \times 2 \mathrm{~cm}$ in diameter, respectively. In both cases, Echinococcus larvae were collected from the cysts. The larvae were identified as Echinococcus ortleppi by morphology and a molecular method (using reduced nicotinamide adenine dinucleotide hydrogenase [NADH] with $99 \%-100 \%$ homology compared with $E$. ortleppi in GenBank). This is the first time that this species has been found in humans in Vietnam.
\end{abstract} Keywords: E. ortleppi, hydatid, Vietnam

\section{Introduction}

Human echinococcosis is a zoonotic infection caused by larval forms (metacestodes) of tapeworms of the genus Echinococcus. The adult stage develops in the small intestine of caniids, and the larval stage develops in the viscera of a variety of mammalian species, including humans. ${ }^{1}$ At present, nine valid species of the genus Echinococcus have been identified in the world, including E. granulosus sensu stricto (G1 [sheep strain], G2 [Tasmanian sheep strain], G3 [buffalo strain]), E. equinus (G4), E. ortleppi (G5), E. canadensis (G6-G10), E. multilocularis, E. vogeli, E. oligarthrus, E. felidis, and E. shiquicus. ${ }^{2-5}$ Two of these species are of special medical importance. These are E. granulosus and E. multilocularis, causing cystic echinococcosis and alveolar echinococcosis in humans, respectively. ${ }^{6}$ The first report of E. ortleppi (genotype G5) was in Italy. ${ }^{7}$ The adult worm is $3-6 \mathrm{~mm}$ in length, including three to four proglottids, and is a common parasite in the intestine of the canine family. Humans are considered aberrant intermediate hosts that acquire the infection through accidental ingestion of parasite eggs that may develop into the larval stage of the parasite (metacestode) in suitable internal organs, mainly the liver and lungs. Growing cysts may also damage surrounding tissues and blood vessels. Any associated clinical problems will be dependent on the number of cysts, their size, location, and rate of growth. The organs most frequently affected are the liver and the lungs in approximately $65 \%$ and $25 \%$ of cases, respectively. ${ }^{8}$ The kidneys, spleen, brain, heart, skeletal system, and musculature tissues can also be affected. ${ }^{6}$ In Italy, the chest X-rays and lung images in 24/28 $(85.7 \%)$ patients found a total of 149 cysts, mostly with hepatic localization $(96 \%) .{ }^{9}$ The lifespan of hydatid cysts of E. granulosus can be as long as 16 years in horses ${ }^{10}$ and 53 years in humans. ${ }^{13}$
Correspondence: Nguyen Van De Department of Parasitology, Hanoi Medical University of Vietnam, No. I Ton That Tung Street, Hanoi 100000-150000, Vietnam

Tel +849 I237 728 I

Email ngvdeyhn@gmail.com 
Reports of echinococcosis in humans have been reviewed by Alvarez Rojas et al, ${ }^{12}$ in livestock by Cardona and Carmena, ${ }^{13}$ and in domestic dogs and wild carnivores by Carmena and Cardona. ${ }^{14,15}$

Echinococcosis is distributed almost worldwide and is especially common in such areas as Australia, Tasmania, New Zealand, Southern and Northern Africa, and South America. ${ }^{6}$ In Asia, echinococcosis has been reported in Japan, China, Korea, Mongolia, Thailand, Indonesia, Bangladesh, and India, ${ }^{16}$ but not in Vietnam.

In 2013, two patients were detected with cystic echinococcosis at the National Hospital of Tuberculosis and Lung Diseases in Hanoi, Vietnam. The main clinical and para-clinical symptoms of the patients were described. In the first patient, samples were collected during surgery for removal of the cyst from the lung, and in the second patient, samples were collected by extracting fluids from the cyst in the lung. Echinococcus antigen in an enzyme-linked immunosorbent assay (ELISA) kit was used for detection of Echinococcus-specific antibodies with cutoff $\mathrm{OD}<0.3$. The ELISA test and morphological identification of species were carried out in the Department of Parasitology, Hanoi Medical University, and the molecular methods were performed in the Molecular Diagnostic Laboratory of the National Hospital of Tropical Diseases. The two patients were followed-up for 2 years after their treatments. These patients are the first reported cases of echinococcosis in Vietnam. Both patients provided written consent to have their data and images published.

\section{Case report Description of the first case}

The first patient was a 42-year old male residing in the Thach Dong commune, Thach Thanh District, Thanh Hoa Province, in the mountainous region of northern Vietnam. He is a farmer and had never left the country. He felt chest pains on his right side in January 2013, and this symptom increased for 2 months; at the end of February 2013, he visited the Provincial Hospital and then the National Hospital of Lung Diseases (Hanoi, Vietnam). The main clinical symptom was pain in the right chest, absence of fever, and no cough or other symptoms. Paraclinical symptoms were a big nodular shadow circle form of equal density in the right lobe of the lungs, detected by chest X-ray examination, of $6 \times 7 \mathrm{~cm}$ size (Figure 1). The leukocyte count was $9,600,000$, including neutrophils $57.4 \%$, lymphocytes $20.6 \%$, eosinophils $12.8 \%$, monocytes $8.3 \%$, and basophils $0.9 \%$; positive serodiagnosis was obtained by ELISA test with Echinococcus antigen. This patient was treated by surgery combined with use of albendazole $800 \mathrm{mg}$ /day for 30 days (three dosages), and he was free of symptoms during the follow-up period of 3 months.

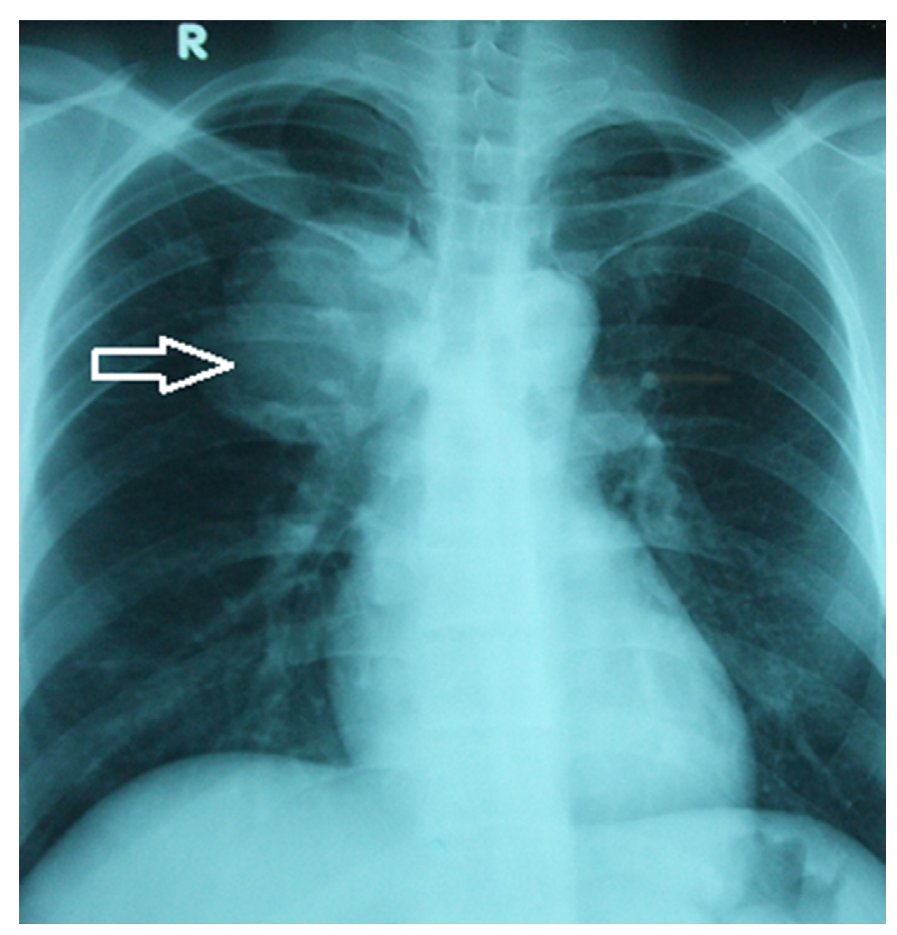

Figure I A hydatid cyst $(6 \times 7 \mathrm{~cm}$ in diameter, arrow $)$ in the lung of the first patient, detected by $X$-ray. 


\section{Description of the second case}

The second patient was a 48-year old female residing in Phu Yen town of the Phu Yen District, Son La Province, also in the mountainous north region of Vietnam. She is a medical technician and had also never left the country. She felt chest pains, along with cough and bloody sputum in June 2013; these symptoms increased for 2 months, and in the middle of August 2013, she visited the Provincial Hospital and then the National Hospital of Lung Diseases (Hanoi, Vietnam). The main clinical symptoms were pain in the chest, dyspnea, and cough with blood, in addition to absence of fever. Paraclinical symptoms were four big nodular shadow circles formed of equal density in both lobes of the lungs, detected by chest X-ray examination, with sizes of $5 \times 6 \mathrm{~cm}, 4 \times 4 \mathrm{~cm}, 3.5 \times$ $3 \mathrm{~cm}$, and $2.5 \times 2 \mathrm{~cm}$ (Figure 2). The leukocyte count was $8,520,000$, including neutrophils $72.0 \%$, lymphocytes $12.9 \%$, eosinophils $8.3 \%$, monocytes $6.7 \%$, and basophils $0.1 \%$; positive serodiagnosis was obtained by ELISA test with
Echinococcus antigen. A microscopic examination of the fluid, extracted from the biggest cyst using a disposable syringe, was performed. The results showed the presence of a large number of Echinococcus larvae. Surgery was not done on this patient because the cysts were found in both lungs. However, she was treated with albendazole $800 \mathrm{mg} /$ day for 30 days (six dosages). She was free of chest pain during the follow-up period of 3 months and free of cough after 12 months; however, the cysts had decreased in size (the remaining two cysts only: 3.5 $\times 2 \mathrm{~cm}$ and $2.5 \times 1.5 \mathrm{~cm}$ in the lungs).

\section{Description of the parasite}

In the cysts (cystic echinococcosis) of both patients were many protoscoleces, each of which had many hooks (Figure 3).

The protoscolex is a spherical body of approximately $0.15 \times 0.14 \mathrm{~mm}$ in diameter, in which an invaginated scolex with 30 hooks and four suckers is contained, and each hook is $22 \mu \mathrm{m}$ in diameter length (Figure 3).

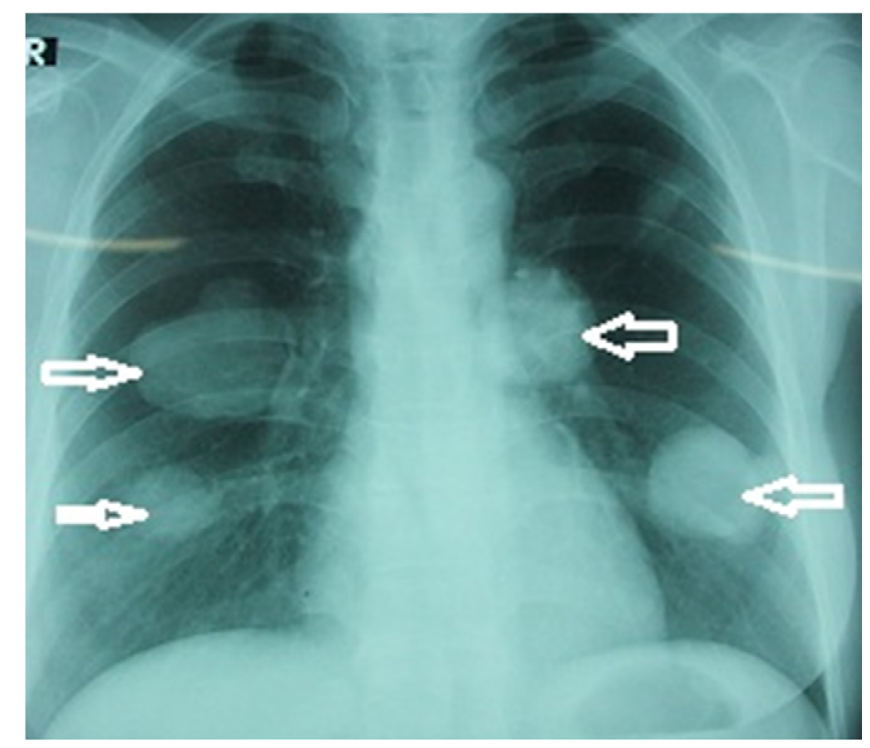

Figure 2 The hydatid cysts (four cysts: $5 \times 6 \mathrm{~cm}, 4 \times 4 \mathrm{~cm}, 3.5 \times 3 \mathrm{~cm}$, and $2.5 \times 2 \mathrm{~cm}$ in diameter, arrows) in the lungs of the second patient, detected by $X$-ray.

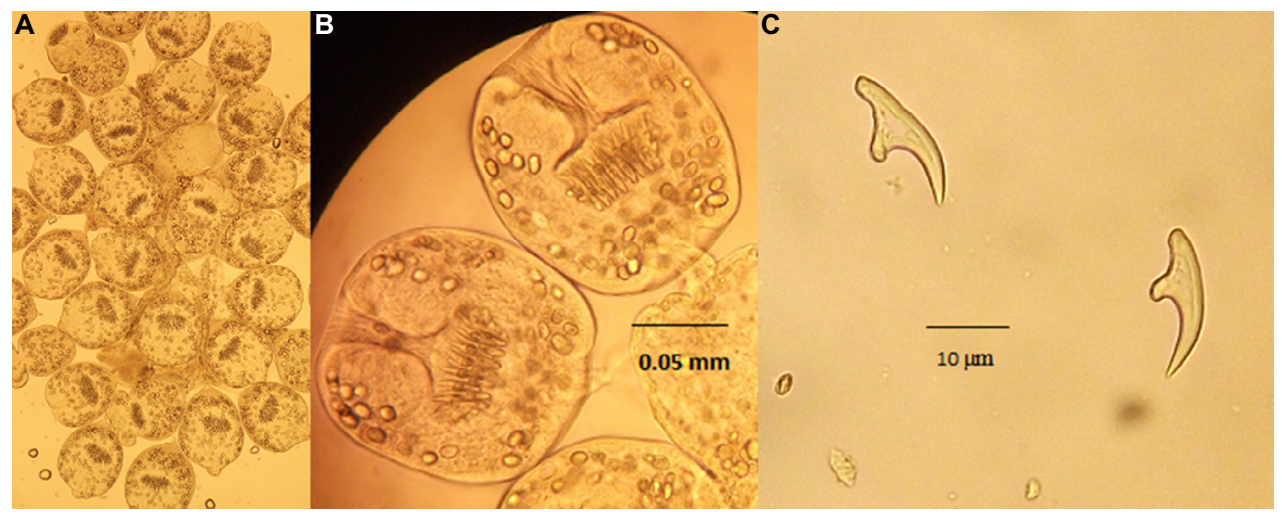

Figure 3 The protoscoleces and the hooklets of Vietnamese Echinococcus.

Notes: (A) The larvae observed by microscopy (I0x); (B) the larvae observed at 40x; (C) the hooks of the larvae observed at $90 \times$. 
Table I Sequencing of NADH dehyrogenase I gene of different Echinococcus spp. from GenBank compared with E. ortleppi* in Vietnam

\begin{tabular}{|c|c|c|c|c|c|c|}
\hline Notation & Origin & Host & Length & Species & $\begin{array}{l}\text { GenBank } \\
\text { number }\end{array}$ & Authors \\
\hline Eorvn I & Vietnam & Human & $438 \mathrm{bp}$ & E. ortleppi* & - & This study \\
\hline Eorvn2 & Vietnam & Human & $438 \mathrm{bp}$ & E. ortleppi* & - & This study \\
\hline Eorl & Sudan & Camel & $438 \mathrm{bp}$ & E. ortleppi & JN637I77.I & Ahmed et $\mathrm{al}^{22}$ \\
\hline Eor2 & Unknown & Cattle & $438 \mathrm{bp}$ & E. ortleppi & AB235846.I & Nakao et $\mathrm{a}^{23}$ \\
\hline Eor3 & The Netherlands & Cattle & $438 \mathrm{bp}$ & E. ortleppi & DQ402037.I & Lavikainen et $\mathrm{al}^{24}$ \\
\hline Eor4 & The Netherlands & Cattle & $438 \mathrm{bp}$ & E. ortleppi & AJ237636.I & Bowles et $\mathrm{al}^{25}$ \\
\hline Eeq5 & Namibia & Zebra & $420 \mathrm{bp}$ & E. equinus & AJ508085.I & Obwaller et a ${ }^{26}$ \\
\hline Eca6 & Finland & Reindeer & $438 \mathrm{bp}$ & E. canadensis & AF525297.I & Lavikainen et $\mathrm{a}^{26}$ \\
\hline Eca7 & Sudan & Camel & $438 \mathrm{bp}$ & E. canadensis & JN637I 76.1 & Ahmed et $\mathrm{al}^{22}$ \\
\hline Egr8 & Iran & Camel & $438 \mathrm{bp}$ & E. granulosus & HM7496I8.I & $\begin{array}{l}\text { Rostami et al, unpublished } \\
\text { data, } 2010\end{array}$ \\
\hline Egr9 & Iran & Camel & $438 \mathrm{bp}$ & E. granulosus & HM7496I7.I & $\begin{array}{l}\text { Rostami et al, unpublished } \\
\text { data, } 2010\end{array}$ \\
\hline Egrlo & Iran & Human & $438 \mathrm{bp}$ & E. granulosus & HM563037.I & $\begin{array}{l}\text { Fasihi et al, unpublished } \\
\text { data, } 2010\end{array}$ \\
\hline Egrll & Poland & Human & $438 \mathrm{bp}$ & E. granulosus & JX266822.I & Dybicz et $\mathrm{al}^{27}$ \\
\hline EgrI2 & Poland & Human & $438 \mathrm{bp}$ & E. granulosus & JX2668I8.I & Dybicz et $\mathrm{al}^{27}$ \\
\hline
\end{tabular}

Notes: *Result after this study. Eorvn I and Eorvn2 are Vietnamese Echinococcus spp. (collected from Patient I and Patient 2); Eorl is Sudanese E. ortleppi (GenBank number: JN637177.I), Eor2 is from an unknown country (GenBank number: AB235846.I), Eor3 and Eor4 are E. ortleppi from the Netherlands (GenBank numbers: DQ402037.I and AJ237636. I); Eeq5 is E. equinus from Namibia (GenBank number: AJ508085. I); Eca6 and Eca7 are E. canadensis from Finland and Sudan (GenBank numbers: AF525297.I and JN637176.I), Egr8, Egr9, and EgrlO are Iranian E. granulosus specimens (GenBank numbers: HM749618.I, HM749617.I, and HM563037.I), and EgrlI and Egrl2 are E. granulosus specimens from Poland (GenBank numbers: JX266822.I and JX2668I8.I.

Abbreviations: bp, base pairs; $\mathrm{NADH}$, reduced nicotinamide adenine dinucleotide.

Table 2 Percentage of identity of nucleotides of NADH dehyrogenase I gene sequences of Vietnamese Echinococcus ortleppi and other Echinococcus spp. in GenBank

\begin{tabular}{|c|c|c|c|c|c|c|c|c|c|c|c|c|c|c|}
\hline & Eorvn I & Eorvn2 & Eor I & Eor2 & Eor3 & Eor4 & Eeq5 & Eca6 & Eca7 & Egr8 & Egr9 & Egrlo & Egr I I & Egr I 2 \\
\hline Eorvn I & & 99 & 99 & 99 & 99 & 99 & 96 & 94 & 94 & 94 & 94 & 93 & 93 & 93 \\
\hline Eorvn2 & 99 & & 99 & 99 & 100 & 99 & 96 & 93 & 93 & 93 & 93 & 93 & 93 & 93 \\
\hline EorI & 99 & 99 & & 100 & 100 & 99 & 96 & 93 & 93 & 93 & 93 & 93 & 93 & 93 \\
\hline Eor2 & 99 & 100 & 100 & & 100 & 99 & 96 & 93 & 93 & 93 & 93 & 93 & 93 & 93 \\
\hline Eor3 & 99 & 100 & 100 & 100 & & 99 & 96 & 93 & 93 & 93 & 93 & 93 & 93 & 93 \\
\hline Eor4 & 99 & 99 & 99 & 99 & 99 & & 96 & 93 & 93 & 93 & 93 & 93 & 93 & 93 \\
\hline Eeq5 & 96 & 96 & 96 & 96 & 96 & 96 & & 93 & 97 & 97 & 97 & 97 & 97 & 97 \\
\hline Eca6 & 94 & 93 & 93 & 93 & 93 & 93 & 97 & & 97 & 97 & 100 & 99 & 99 & 99 \\
\hline Eca7 & 94 & 93 & 93 & 93 & 93 & 93 & 97 & 100 & & 100 & 100 & 99 & 99 & 99 \\
\hline Egr8 & 94 & 93 & 93 & 93 & 93 & 93 & 97 & 100 & 100 & & 100 & 99 & 99 & 99 \\
\hline Egr9 & 94 & 93 & 93 & 93 & 93 & 93 & 97 & 100 & 100 & 99 & & 99 & 99 & 99 \\
\hline Egrlo & 93 & 93 & 93 & 93 & 93 & 93 & 97 & 99 & 99 & 99 & 99 & & 99 & 100 \\
\hline EgrlI & 93 & 93 & 93 & 93 & 93 & 93 & 97 & 99 & 99 & 99 & 99 & 100 & & 100 \\
\hline Egr|2 & 93 & 93 & 93 & 93 & 93 & 93 & 97 & 99 & 99 & 99 & 99 & 100 & 100 & \\
\hline
\end{tabular}

Notes: EorvnI and Eorvn2 are Vietnamese Echinococcus spp. (collected from Patient I and Patient 2); Eor I is Sudanese E. ortleppi (GenBank number: JN637I77.I), Eor2 is from an unknown country (GenBank number: AB235846.I), Eor3 and Eor4 are E. ortleppi from the Netherlands (GenBank numbers: DQ402037.I and AJ237636.I); Eeq5 is E. equinus from Namibia (GenBank number: AJ508085.I); Eca6 and Eca7 are E. canadensis from Finland and Sudan (GenBank numbers: AF525297.I and JN637I76.I), Egr8, Egr9, and Egr IO are Iranian E. granulosus specimens (GenBank numbers: HM7496I8. I, HM7496I7.I, and HM563037.I), and Egr I I and Egr I 2 are E. granulosus specimens from Poland (GenBank numbers: JX266822.I and JX2668I8.I.

Abbreviation: $\mathrm{NADH}$, reduced nicotinamide adenine dinucleotide.

These protoscoleces were analyzed by a molecular method using the gene of NADH hydrogenasa. The result identified them as E. ortleppi with $99-100 \%$ homology compared with E. ortleppi in GenBank, but only homology with E. granulosus was 93-94\% (Tables 1 and 2). The phylogenetic tree of E. ortleppi Vietnam and other strains derived from part of the NADH dehydrogenase nucleotide sequence and the COX1 gene, determined by neighbor-joining (NJ) method using MEGA5.1, ${ }^{6}$ showed that the strain of Vietnamese $E$. ortleppi belongs to the same group as strains of $E$. ortleppi in GenBank (Figures 4 and 5).

\section{Discussion}

The two cases of echinococcosis in Vietnam were clearly diagnosed because larvae were detected in the cysts from both patients. X-ray diagnosis clearly showed one cyst of $6 \times 7 \mathrm{~cm}$ 


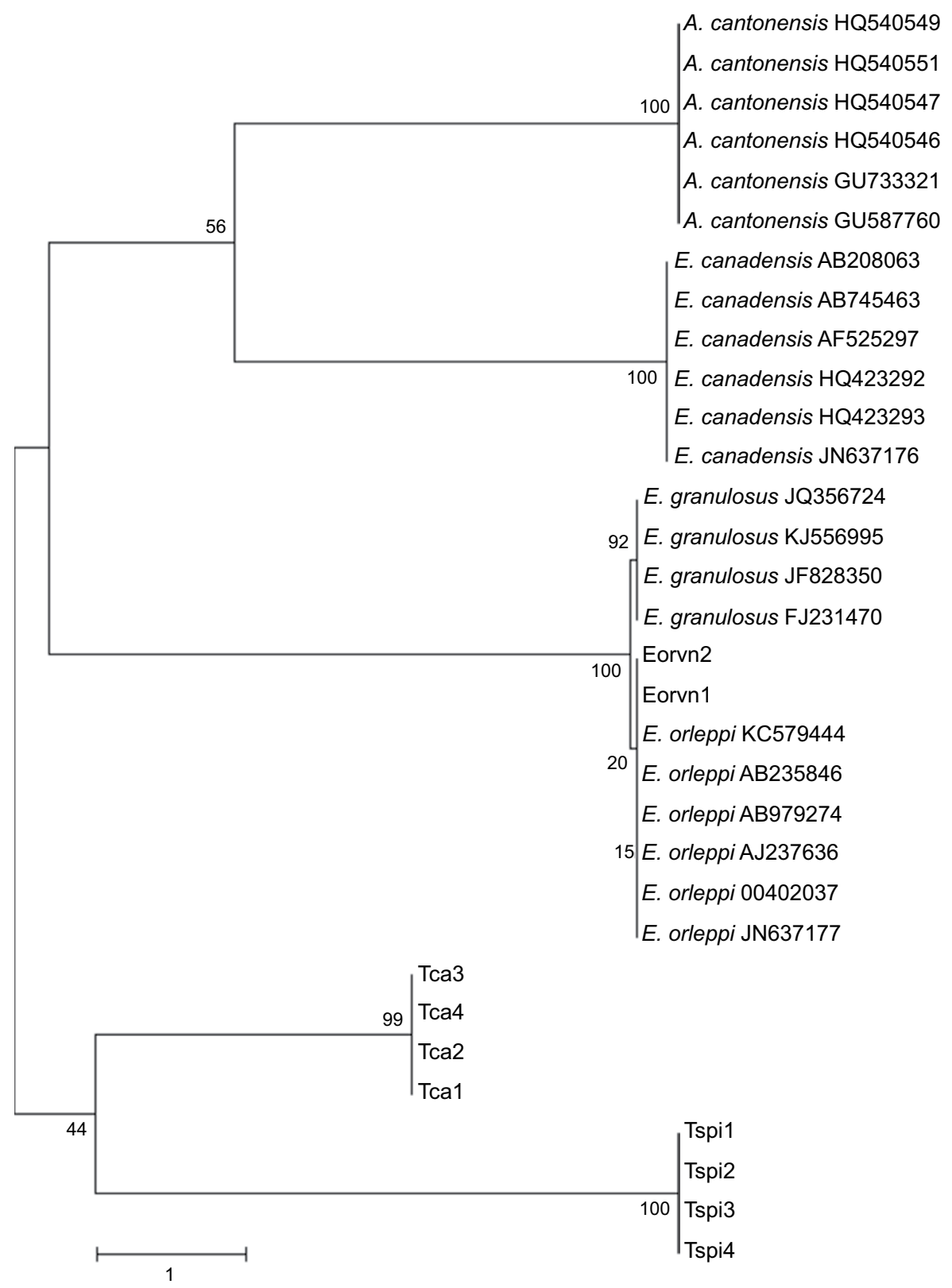

Figure 4 Phylogenetic tree of Echinococcus ortleppi Vietnam and other strains derived from part of NADH dehydrogenase nucleotide sequence estimated by neighbor-joining (NJ) method using MEGA5.I.

Notes: Eorvn I, Eorvn2 = Vietnamese Echinococcus; Tspi I, Tspi2, Tspi3, Tspi4 = Chinese Trichinella spiralis (GenBank numbers: GU339148. I, GU339147.I, GU339146. I, and GU339I45. I, respectively). Tcal, Tca2, Tca3, and Tca4 are Toxocara canis species (GenBank numbers: JF837I70. I, JF837I69.I, JN617989.I, and FJ4 I8788. I, respectively). E. ortleppi are from Argentina (GenBank number: KC579444.I), Japan (GenBank numbers: AB235846.I and AB979274.I), the Netherlands (GenBank numbers: AJ237636.I and DQ402037.I), and Sudan (GenBank number: JN637 I77.I). E. granulosus samples are from France (GenBank number: JQ356724.I), China (GenBank number: KJ556995.I), Brazil (GenBank number: JF828350.I), and Estonia (GenBank number: FJ231470.I). Echinoccus canadensis is from Kazakhstan (GenBank number: AB208063.1), Finland (GenBank numbers: AB745463.I and AF525297.I), Canada (GenBank numbers: HQ423292.I and HQ423293.I), and Sudan (GenBank number: JN637I76.I). Angiostrongylus cantonensis is from China (GenBank numbers: HQ54055I.I, HQ540547.I, and HQ540546, respectively), Brazil (GenBank number: GU73332I.I), and the USA (GenBank number: GU587760.I).

Abbreviation: $\mathrm{NADH}$, reduced nicotinamide adenine dinucleotide.

in the first patient and four cysts with $2 \times 3 \mathrm{~cm}, 3.5 \times 4 \mathrm{~cm}$, $5 \times 6.5 \mathrm{~cm}$, and $6 \times 6.5 \mathrm{~cm}$ in the second patient. In Vietnam, in 2009, De and Khue reported a case, in which a $3 \times 3.5 \mathrm{~cm}$ cyst in the lung was suspected as echinococcosis and which yielded a positive ELISA test with Echinococcus antigen. ${ }^{18}$ However, no larvae were collected from the cyst. In recent years, some suspected cases of water cysts in the liver were diagnosed as echinococcosis by ultrasonography, but again no larvae or hooks were collected in the fluid from the cysts. In 1967, Le-Van-Hoa and Vu-Ngoc-Tan ${ }^{19}$ reported on dogs that were infected with $E$. granulosus in southern Vietnam and that served as definitive hosts, which could transmit the disease to humans.

Echinococcus ortleppi is a cattle strain (genotype G5) of E. granulosus occurring in Europe, ${ }^{4,28}$ which is infective 


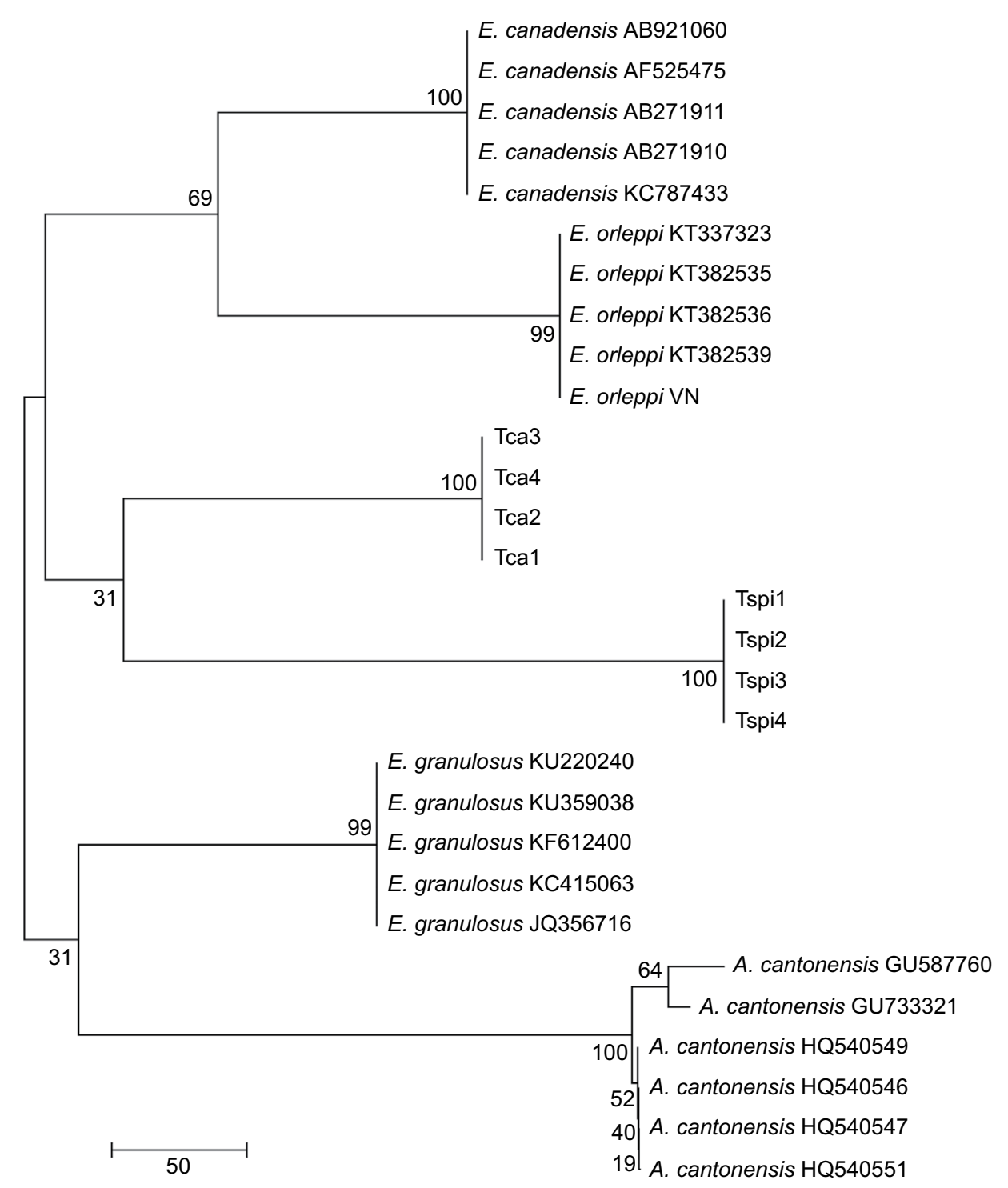

Figure 5 Phylogenetic tree of Echinococcus ortleppi Vietnam and other strains derived from part of cytochrome $C$ oxidase subunit I nucleotide sequence, estimated by neighbor-joining (NJ) method using MEGA5.I.

Notes: E. ortleppi VN = Vietnamese Echinococcus; Tspi I, Tspi2, Tspi3, and Tspi4 = Chinese Trichinella spiralis (GenBank numbers: GU339|48.I, GU339I47.I, GU339I46.I, and GU339145.I, respectively). Tca I, Tca2, Tca3, and Tca4 are Toxocara canis species (GenBank numbers: JF837I 70. I, JF837I69.I, JN6I7989.I, and FJ4I8788.I, respectively). E. ortleppi samples are from Brazil (GenBank numbers: KT337323.I, KT382536.I, KT382535.I, and KT382539.I, respectively). Echinococus canadensis is from Egypt (GenBank number: AB921060.I), Finland (GenBank number: AF525475.I), Sudan (GenBank numbers: AB27I9II.I and AB27I9I0.I), and Brazil (GenBank number: KC787433.I). E. granulosus samples are from Iran (GenBank numbers: KU220240.I, KU359038.I, and KF6I2400.I), India (GenBank number: KC4I5063.I), and France (GenBank number: JQ3567I6.I). Angiostrongylus cantonensis samples are from China (GenBank numbers: HQ54055I.I, HQ540547.I, and HQ540546, respectively), Brazil (GenBank number: GU73332I.I), and the USA (GenBank number: GU587760.I).

to humans. Genotype G5 of E. ortleppi was detected for the first time in Italy in 2008 by Casulli et al, ${ }^{7}$ and cystic echinococcosis caused by its larval stage was found to be endemic in southern Brazil by Balbinotti et al in 2012. ${ }^{3}$ In 2011 and 2012, liver infections caused by E. ortleppi tapeworms were diagnosed in two humans in France, and in 2012, a nationwide slaughterhouse survey identified $E$. ortleppi infections in cattle. ${ }^{20}$ Echinococcosis in livestock caused by E. ortleppi was described in Kenya, Sudan, India, Italy, Argentina, and Brazil. ${ }^{13,14}$ More recent studies have reported the presence of this Echinococcus spp. in Ethiopia, ${ }^{30}$ Egypt,${ }^{31}$ and France. ${ }^{7}$

\section{Conclusion}

In 2013, two cases of infection by E. ortleppi that caused cystic echinococcosis in the lungs were reported in Vietnam. This was the first time that this species was detected in humans in Vietnam.

\section{Acknowledgments}

This research was funded by the Vietnam National Foundation for Science and Technology Development (NAFOSTED) under grant number 106-YS.05-2014.08, in collaboration with the National Hospital of Tuberculosis and Lung Diseases, Hanoi, Vietnam. 


\section{Disclosure}

The authors report no conflicts of interest in this work.

\section{References}

1. De NV, Khue PV. Zoonotic Parasites. Scientific Book. Vietnam: Education Published House; 2009:116-117.

2. De NV, Le TH. Taeniasis/Cysticercosis and Molecular Amplication. Scientific Book Medical Published House; 2010:163-165.

3. Balbinotti H, Santos GB, Badaraco J, et al. Echinococcus ortleppi (G5) and echinococcus granulosus sensu stricto (G1) loads in cattle from Southern Brazil. Vet Parasitol. 2012;188(3-4):255-260.

4. Nakao M, Lavikainen A, Yanagida T, Ito A. Phylogenetic systematics of the genus Echinococcus (Cestoda: Taeniidae). Int J Parasitol. 2013;43(12-13):1017-1029.

5. Saarma U, Jõgisalu I, Moks E, et al. A novel phylogeny for the genus Echinococcus, based on nuclear data, challenges relationships based on mitochondrial evidence. Parasitology. 2009;136(3):317-328.

6. Tamura K, Nei M, Kumar S. Prospects for inferring very large phylogenies by using the neighbor-joining method. Proc Natl Acad Sci USA. 2004;101(30):11030-11035.

7. Miyazaki I. Helminthic zoonoses. International Medical Foundation of Japan. Tokyo; 1991:247-258.

8. Casulli A, Manfredi MT, La Rosa G, Cerbo AR, Genchi C, Pozio E. Echinococcus ortleppi and E. granulosus G1, G2 and G3 genotypes in Italian bovines. Vet Parasitol. 2008;155(1-2):168-172.

9. de la Rue ML, Takano K, Brochado JF, et al. Infection of humans and animals with Echinococcus granulosus (G1 and G3 strains) and E. ortleppi in Southern Brazil. Vet Parasitol. 2011;177(1-2):97-103.

10. Schwabe CW. Current status of hydatid disease: a zoonosis of increasing importance. In: Thompson RCA, editors. The Biology of Echinococcus and Hydatid Disease, London: George Allen \& Unwin; 1986: 81-113.

11. Linda P, Gilda C, Lidia C, et al. Cystic echinococcosis i n a single tertiary care center in Rome, Italy. Bio Med Res Int. 2013; Article ID 978146, 9 pages.

12. Roneus O, Christensson D, Nilsson NG. The longevity of hydatid cysts in horses. Vet. Parasitol. 1982;11(2-3):149-154.

13. Spruance SL. Latent period of 53 years in a case of hydatid cyst disease. Arch Intern Med. 1974;134(4):741-742.

14. Alvarez Rojas CA, Romig T, Lightowlers MW. Echinococcus granulosus sensu lato genotypes infecting humans-review of current knowledge. Int J Parasitol. 2014;44(1):9-18.

15. Cardona GA, Carmena D. A review of the global prevalence, molecular epidemiology and economics of cystic echinococcosis in production animals. Vet Parasitol. 2013;192(1-3):10-32.
16. Carmena D, Cardona GA. Canine echinococcosis: global epidemiology and genotypic diversity. Acta Trop. 2013;128(3):441-460.

17. Carmena D, Cardona GA. Echinococcosis in wild carnivorous species: epidemiology, genotypic diversity, and implications for veterinary public health. Vet Parasitol. 2014;202(3-4):69-94.

18. Ito A, Wen H, Yamazaki H. Taeniasis/cysticercosis and echinococcosis in Asia. Asian Pasasitology. 2005;2:155-234.

19. Ahmed ME, Eltom KH, Musa NO, et al. First report on cerculation of echinococcus ortleppi in the one humped camel (camelus dromedaries), Sudan. BMC Vet Res. 2013;9:127.

20. Bowles J, McManus DP. NADH dehydrogennase 1 gene sequences compared for species and strains of the genus Echinococcus. Int $J$ Parasitol. 1993;23(7):969-972.

21. Dybiez M, Gierczak A, Dabrwoska J, RdzanckI, Michalowicz B. Molecular diagnosis of cystic echinococcosis in human from central Poland. Prasitol Int. 2013;62(4):364-367.

22. Fasihi MH, Budke CM, Rostami S. The monetary burden of cystic echinococcosis in Iran. PLoS Negl Trop Dis. 2012;6(11):e1915.

23. Nakao M, McManus PD, Schantz PM, Craig PS, Ito A. A molecular phylogeny of the genus Echinococcus inferred from complete mitochondrial genom. Parasitology. 2007;134(Pt 5):713-722.

24. Lavikainen A, Lehtinen MJ, Laaksonen S, Agren E, Oksanen A, Meri S. Molecular characherization of Echinococcus isolates of cervid origin from Finland and Sweden. Parsitology. 2006;133(Pt 5):713-722.

25. Lavikainen A, Lehtinen MJ, Meri T, Hirvenla-KoskiV, Meri S. Molecular genetic characherization of Fennoscandial cervid strain, a new genotypic group(G10) of Echinococcus granulosus. Parsitology. 2003;127(Pt 5):207-215.

26. Obwaller A, Schneider R, Walochnik J, et al. Echinococcus granulosus strain differentiation based on sequence heterogeneity in mitochondrial genesof cytocrome c oxydaza-1 and NADH dehydrogenase 1. Parsitology. 2004;128(Pt 5):569-575.

27. Hoa LV, Tan VN. Concerning the pesence of cestodes, Echinococcus granulosus (Batsch, 1786), in a wild dog, Cyon primaerus (Hodgs) in South Vietnam. Bull Soc Pathol Exot Filiales. 1967;60(1):64-71. French.

28. Thompson RCA. The taxonomy, phylogeny and transmission of Echinococcus. Exp Parasitol. 2008;119(4):439-446.

29. Grenouillet F, Umhang G, Arbez-Gindre F, et al. Echinococcus ortleppi infections in humans and cattle, France. Emerg Infect Dis. 2014;20(12):2100-2102.

30. Tigre W, Deresa B, Haile A, et al. Molecular characterization of Echinococcus granulosus s.l. cysts from cattle, camels, goats and pigs in Ethiopia. Vet Parasitol. 2016;215:17-21.

31. Amer S, Helal IB, Kamau E, Xiao L. Molecular characterization of Echinococcus sensu lato from farm animals in Egypt. PLoS One. 2015;10(3):e0118509.
Research and Reports in Tropical Medicine

\section{Publish your work in this journal}

Research and Reports in Tropical Medicine is an international, peerreviewed, open access journal publishing original research, case reports, editorials, reviews and commentaries on all areas of tropical medicine, including: Diseases and medicine in tropical regions; Entomology; Epidemiology; Health economics issues; Infectious disease; Laboratory

\section{Dovepress}

science and new technology in tropical medicine; Parasitology; Public health medicine/health care policy in tropical regions; and Microbiology. The manuscript management system is completely online and includes a very quick and fair peer-review system. Visit http://www.dovepress. com/testimonials.php to read real quotes from published authors. 